\title{
Insulin resistance reduces arterial prostacyclin synthase and eNOS activities by increasing endothelial fatty acid oxidation
}

\author{
Xueliang Du, ${ }^{1}$ Diane Edelstein, ${ }^{1}$ Silvana Obici, ${ }^{2}$ Ninon Higham, ${ }^{1}$ \\ Ming-Hui Zou, ${ }^{3}$ and Michael Brownlee ${ }^{1}$
}

\begin{abstract}
${ }^{1}$ Diabetes Research Center, Albert Einstein College of Medicine, New York, New York, USA. ²Genome Research Institute, University of Cincinnati,
\end{abstract} Cincinnati, Ohio, USA. ${ }^{3}$ Division of Endocrinology and Diabetes, University of Oklahoma Health Science Center, Oklahoma City, Oklahoma, USA.

\begin{abstract}
Insulin resistance markedly increases cardiovascular disease risk in people with normal glucose tolerance, even after adjustment for known risk factors such as LDL, triglycerides, HDL, and systolic blood pressure. In this report, we show that increased oxidation of FFAs in aortic endothelial cells without added insulin causes increased production of superoxide by the mitochondrial electron transport chain. FFA-induced overproduction of superoxide activated a variety of proinflammatory signals previously implicated in hyperglycemiainduced vascular damage and inactivated 2 important antiatherogenic enzymes, prostacyclin synthase and eNOS. In 2 nondiabetic rodent models - insulin-resistant, obese Zucker ( $\mathrm{fa} / \mathrm{fa})$ rats and high-fat diet-induced insulin-resistant mice - inactivation of prostacyclin synthase and eNOS was prevented by inhibition of FFA release from adipose tissue; by inhibition of the rate-limiting enzyme for fatty acid oxidation in mitochondria, carnitine palmitoyltransferase I; and by reduction of superoxide levels. These studies identify what we believe to be a novel mechanism contributing to the accelerated atherogenesis and increased cardiovascular disease risk occurring in people with insulin resistance.
\end{abstract}

\section{Introduction}

Insulin resistance (IR) occurs in the majority of patients with type 2 diabetes, and in two-thirds of subjects with impaired glucose tolerance (1). Both these groups have a significantly higher risk of developing cardiovascular disease (CVD) (2-5). In order to isolate the effects of IR from those of hyperglycemia and diabetes, several studies have evaluated subjects with normal glucose tolerance. In nonobese subjects without diabetes, IR predicted the development of CVD independently of other known risk factors (6). In another group of subjects without diabetes or impaired glucose tolerance, those in the highest quintile of IR had a 2.5-fold increase in CVD risk compared with those in the lowest quintile (7). These data indicate that IR itself promotes atherogenesis.

IR is commonly associated with a proatherogenic dyslipidemia, which data from Brown, Goldstein, and colleagues suggest results from hyperinsulinemia-induced activation of SREBP-1c transcription in the liver by a mechanism that is not affected by the defects in hepatic PI3K-mediated insulin signaling $(8,9)$. Surprisingly, however, in subjects without diabetes or impaired glucose tolerance, after adjustment for 11 known cardiovascular risk factors, including LDL, triglycerides, HDL, systolic blood pressure, and smoking, the most insulin-resistant subjects still had a 2 -fold increase in the risk of CVD (7). This observation

Nonstandard abbreviations used: AGE, advanced glycation end product; BAEC, bovine aortic endothelial cell; CPT-I, carnitine palmitoyltransferase I; CVD, cardiovascular disease; $\mathrm{FADH}_{2}$, the reduced form of flavin adenine dinucleotide; $f a / f a$, obese Zucker; IR, insulin resistance; IRS, insulin receptor substrate; MnSOD, manganese superoxide dismutase; MnTBAP, manganese (III) tetrakis(4-benzoic acid) porphyrin; $\mathrm{NA}$, nicotinic acid; $\mathrm{PGI}_{2}$, prostacyclin; $\mathrm{SOD}$, superoxide dismutase; TCA, tricarboxylic acid; TDGA, tetradecylglycidate; UCP-1, uncoupling protein 1 .

Conflict of interest: The authors have declared that no conflict of interest exists. Citation for this article: J. Clin. Invest. 116:1071-1080 (2006). doi:10.1172/JCI23354 suggested to us that a large part of the increased CVD risk due to IR reflects a consequence of IR not previously identified as being proatherogenic.

Since hyperglycemia has been found to cause overproduction of superoxide by the mitochondrial electron transport chain in endothelial cells, which then activates all the known pathways of microvascular damage (10-12), and since oxidation of FFAs provides the same electron donors (NADH and the reduced form of flavin adenine dinucleotide, $\mathrm{FADH}_{2}$ ) to the mitochondrial electron transport chain that oxidation of glucose does, we hypothesized that the increase in FFA flux caused by increased FFA release from adipocytes resistant to insulin's antilipolytic effects (13) would result in increased FFA oxidation in arterial endothelial cells (Figure 1). We further hypothesized that the PI3K pathway-specific IR described in aortae from a genetic model of IR (14) would allow further increased FFA oxidation in these cells, since it would significantly block insulin's normal inhibitory effect on fatty acid oxidation (15). Abnormally increased FFA oxidation in arterial endothelial cells would lead to overproduction of superoxide by the mitochondrial electron transport chain, with resultant activation of a variety of proinflammatory pathways $(11,16)$, and inactivation of 2 important antiatherogenic factors, prostacyclin $\left(\mathrm{PGI}_{2}\right)$ synthase $(17,18)$ and eNOS (19-23). The critical role of these 2 enzymes in atherogenesis has been recently demonstrated using gene knockout models: apoE $E^{-/-}$prostacyclin receptor ${ }^{-1-}$ mice showed significant acceleration of atherosclerosis compared with apo $E^{-/-}$alone (24), and apoE $E^{-/}$ eNOS $S^{-/}$mice also showed accelerated atherosclerosis compared with apoE $E^{-/-}$alone (23). In humans, reduced NO production by eNOS is a significant risk factor for CVD as well $(25,26)$.

To test this hypothesis, we first examined the effects of FFA on ROS production in arterial endothelial cells cultured in $5 \mathrm{mM}$ glucose without added insulin and with insulin in the presence 


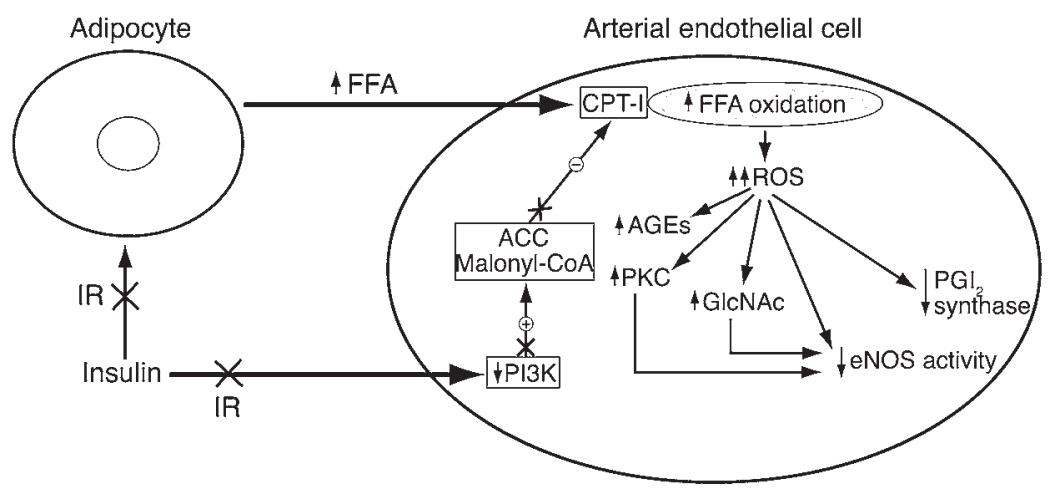

Figure 1

Schematic mechanism by which IR causes increased oxidation of FFA in arterial endothelial cells, activating proatherogenic signals and inhibiting antiatherogenic enzymes. IR, insulin resistance; ACC, acetyl-CoA carboxylase; CPT-I, carnitine palmitoyltransferase I; AGE, advanced glycation end product; GlcNAc, N-acetylglucosamine; $\mathrm{PGI}_{2}$, prostacyclin.

of a PI3K inhibitor, to model IR. We next investigated the mechanism by which FFA induces overproduction of ROS in these cells using inhibitors of carnitine palmitoyltransferase I (CPT-I), mitochondrial electron transport chain generation of superoxide, and superoxide accumulation.

Hyperglycemia-induced superoxide production inhibits GAPDH activity by causing ADP-ribosylation of the enzyme (12). This decrease in GAPDH activity activates multiple pathways implicated in diabetic vascular damage (12). For example, GAPDH inhibition-induced PKC activation leads to activation of a variety of proinflammatory processes (11), and a GAPDH inhibition-induced increase in advanced glycation end product (AGE) formation induces VCAM-1 expression, a marker of the early stages of atherosclerosis (16). Therefore, we next examined the effect of FFA-induced ROS on GAPDH activity and subsequently on each of these damaging pathways. The effects of FFA-induced ROS on the activity of 2 critical antiatherogenic enzymes - $\mathrm{PGI}_{2}$ synthase and eNOS - were then investigated in cultured arterial endothelial cells. $\mathrm{PGI}_{2}$ synthase activity was assessed in vivo after fatty acid infusion in rats. Finally, the in vivo effects of FFA-induced ROS on aortic $\mathrm{PGI}_{2}$ synthase activity and eNOS were evaluated in 2 different animal models of IR - the obese Zucker rat ( $f a / f a$ rat; homozygous for the mutant allele) (27), and the high-fat diet-induced insulin-resistant mouse $(28,29)$.

\section{Figure 2}

Effect of FFAs on ROS production by endothelial cells. (A) Effect of FFAs on ROS production in arterial cells cultured in $5 \mathrm{mM}$ glucose. Cells were incubated in $5 \mathrm{mM}$ glucose without added insulin, plus the indicated concentrations of oleic acid (bars 1-4), and with oleic acid plus $3 \mathrm{nM}$ insulin with and without pretreatment with $100 \mathrm{nM}$ wortmannin (bars 5 and 6). Each bar represents the mean plus SEM of 4 separate experiments, each with $n=8$. ${ }^{*} P<0.01$ compared with cells incubated in $5 \mathrm{mM}$ glucose alone. (B) Effect of FFAs on ROS production in retinal capillary endothelial cells cultured in $5 \mathrm{mM}$ glucose. Cells were incubated in $5 \mathrm{mM}$ glucose, $30 \mathrm{mM}$ glucose, or $5 \mathrm{mM}$ glucose plus oleic acid. Each bar represents the mean plus SEM of 4 separate experiments, each with $n=8$. ${ }^{\star} P<0.01$ compared with cells incubated in $5 \mathrm{mM}$ glucose alone.

\section{Results}

Effect of FFAs on ROS production in arterial cells cultured in $5 \mathrm{mM}$ glucose without insulin. As a cell culture model of IR, bovine aortic endothelial cells (BAECs) in $5 \mathrm{mM}$ glucose without added insulin were incubated with different concentrations of oleic acid (Figure 2). Lower physiologic concentrations of oleic acid had no effect on ROS production (Figure 2A, bars 2 and 3). In contrast, incubation with higher physiologic concentrations of oleic acid similar to those found in insulin-resistant subjects increased ROS production in cells cultured in $5 \mathrm{mM}$ glucose severalfold compared with cells cultured in $5 \mathrm{mM}$ glucose alone, from $38 \pm 1 \mathrm{nmol} / \mathrm{ml}$ (Figure $2 \mathrm{~A}$, bar 1 ) to $100 \pm 8 \mathrm{nmol} / \mathrm{ml}$ for $800 \mu \mathrm{M}$ oleic acid (Figure 2A, bar 4). Addition of insulin completely prevented increases in ROS production by $800 \mu \mathrm{M}$ oleic acid (Figure 2A, bar 5), an effect that was reversed by addition of the PI3K inhibitor wortmannin (Figure 2A, bar 6). In these experiments, we used $1,000 \mu \mathrm{M}$ of fatty acid-free albumin, a concentration somewhat higher than the normal range $(530-833 \mu \mathrm{M})$, to ensure that the FFA fraction (the fraction unbound to albumin) would be similar to that found in insulin-resistant humans. In a separate experiment (data not shown), we found that reducing the concentration of fatty acid-free albumin while keeping the oleic acid concentration constant increased ROS production proportionally. This shows that the concentration of free, rather than total, fatty acids determines ROS production in aortic endothelial cells. Unlike hyperglycemia, which increases ROS production in both macrovascular and microvascular endothelial cells (10), FFA had no effect on ROS production by retinal microvascular endothelial cells (Figure 2B). At $30 \mathrm{mM}$ glucose, exposure to $800 \mu \mathrm{M}$ oleic acid caused a reduction of glucose flux through the tricarboxylic acid (TCA) cycle by $40 \%$. However, this was still 3.7 -fold higher than glucose flux at $5 \mathrm{mM}$ (data not shown).

Effect of CPT-I inbibition, uncoupling protein 1, and manganese superoxide dismutase on FFA-induced ROS production. To test our hypothesis that FFAs increase arterial endothelial cell ROS production by pro-
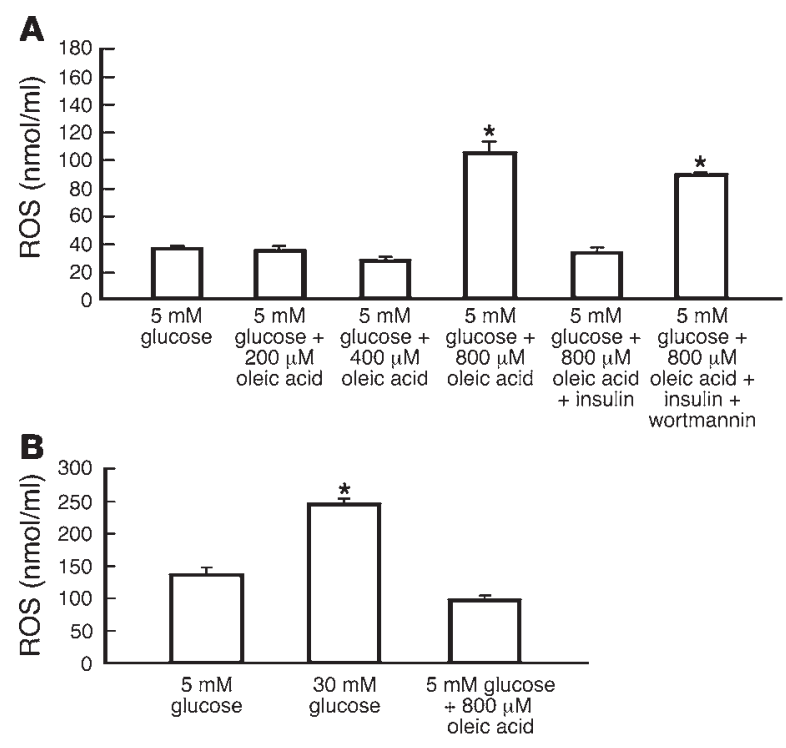


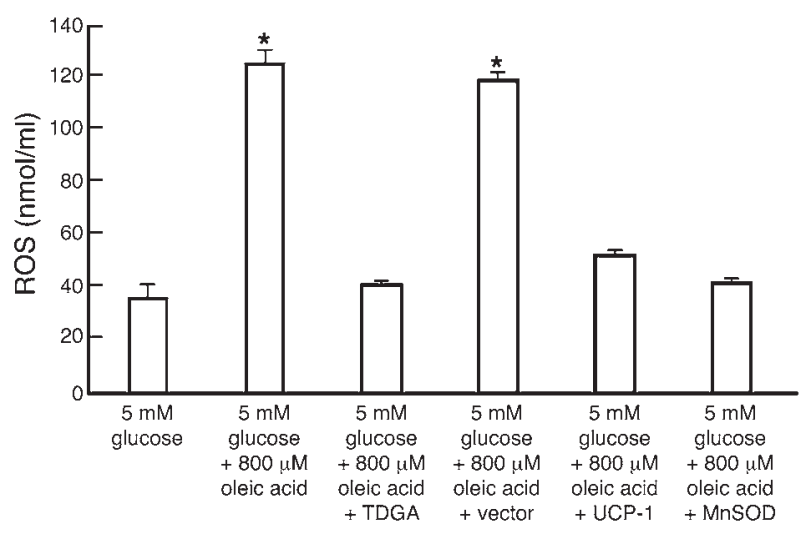

Figure 3

Effect of CPT-I inhibition, UCP-1, and MnSOD on FFA-induced ROS production. Cells were incubated in $5 \mathrm{mM}$ glucose alone or in $5 \mathrm{mM}$ glucose plus either oleic acid alone or oleic acid plus either tetradecylglycidate (TDGA), adenoviral vectors expressing uncoupling protein 1 (UCP-1), or adenoviral vectors expressing manganese superoxide dismutase (MnSOD). Each bar represents the mean plus SEM of 4 separate experiments, each with $n=8$. ${ }^{*} P<0.01$ compared with cells incubated in $5 \mathrm{mM}$ glucose alone.

viding increased electron donors ( $\mathrm{NADH}$ and $\mathrm{FADH}_{2}$ ) to the mitochondrial electron transport chain, the same mechanism previously shown to underlie hyperglycemia-induced ROS production (10), we first inhibited CPT-I with tetradecylglycidate (TDGA). Inhibition of this mitochondrial membrane enzyme, which catalyzes the rate-limiting step of fatty acid oxidation, completely inhibited FFA-induced ROS production by arterial endothelial cells cultured in $5 \mathrm{mM}$ glucose (Figure 3). Eight hundred micromolar oleic acid increased ROS production 3-fold, from $39 \pm 1 \mathrm{nmol} / \mathrm{ml}$ (Figure 3, bar 1) to $119 \pm 2 \mathrm{nmol} / \mathrm{ml}$ (Figure 3, bar 2). However, when CPT-I was inhibited, the same concentration of oleic acid had no effect (Figure 3, bar 3). This shows that FFA-induced ROS production requires fatty acid oxidation. FFA-induced ROS production was similarly prevented in cells exposed to $800 \mu \mathrm{M}$ oleic acid by overexpression of either uncoupling protein 1 (UCP-1) (Figure 3, bar 5), a specific protein uncoupler of oxidative phosphorylation capable of collapsing the proton electrochemical gradient that drives superoxide production (10), or manganese superoxide dismutase (MnSOD) (11), the mitochondrial isoform of this enzyme (Figure 3, bar 6). These data show that the mitochondrial electron transport chain is the source of FFA-induced ROS production, and that the initial ROS formed is superoxide.

Effect of FFA-induced ROS production on GAPDH activity, PKC activity, hexosamine pathway activity, and AGE formation. Since hyperglycemia-induced overproduction of superoxide by the mitochondrial electron transport chain has previously been shown to activate 3

\section{Figure 4}

Effect of FFA-induced ROS production on GAPDH activity, PKC activity, and hexosamine pathway activity. Cells were incubated in $5 \mathrm{mM}$ glucose alone or in $5 \mathrm{mM}$ glucose plus either oleic acid alone or oleic acid plus TDGA or adenoviral vectors expressing UCP-1 or MnSOD. (A) GAPDH activity. (B) PKC activity. (C) Immunoreactive proteinbound $N$-acetylglucosamine (GlcNAc). Each bar represents the mean plus SEM of 3 separate experiments, each with $n=3$. * $P<0.01 \mathrm{com}$ pared with cells incubated in $5 \mathrm{mM}$ glucose alone. major pathways of hyperglycemic damage in endothelial cells by inhibition of GAPDH activity (12), we next examined the effect of FFA-induced ROS production on these same parameters. Like hyperglycemia (12), $800 \mu \mathrm{M}$ oleic acid decreased GAPDH activity by about $60 \%$ (Figure 4A, bar 2). FFA-induced inhibition of GAPDH was associated with activation of PKC (Figure 4B, bar 2), activation of the hexosamine pathway (Figure 4C, bar 2), and increased AGE formation. Inhibition of CPT-I prevented FFA-induced inhibition of GAPDH activity (Figure 4A, bar 3), and the downstream effect of GAPDH inhibition, activation of PKC (Figure 4B, bar 3), activation of the hexosamine pathway (Figure 4C, bar 3), and increased AGE formation. Overexpression of UCP-1 or MnSOD also completely prevented FFA-induced GAPDH inhibition (Figure 4A, bars 5 and 6), PKC activation (Figure 4B, bars 5 and 6), and hexosamine pathway activity (Figure 4C, bars 5 and 6). FFA-induced formation of AGEs was similarly inhibited by overexpression of UCP-1 or MnSOD (data not shown).

Effect of FFA-induced ROS production on $P I_{2}$ synthase activity in aortic endothelial cells. $\mathrm{PGI}_{2}$, produced mainly in endothelial cells, is, like eNOS-derived NO, an endogenous inhibitor of platelet aggregation and SMC proliferation. It is also a potent vasodilator (18). Since hyperglycemia inactivates $\mathrm{PGI}_{2}$ in aortic endothelial cells by reactive oxygen-mediated tyrosine nitration (17), we next examined the effects of FFA-induced ROS on both $\mathrm{PGI}_{2}$ synthase activity and $\mathrm{PGI}_{2}$ synthase tyrosine nitration. In cells cultured in $5 \mathrm{mM}$ glucose, $800 \mu \mathrm{M}$ oleic acid decreased $\mathrm{PGI}_{2}$ synthase activity by $95 \%$ (Figure $5 \mathrm{~A}$, bar 2 ). $\mathrm{PGI}_{2}$ protein levels did not change in the presence of oleic acid (data not shown). This inhibition was completely prevented by CPT-I
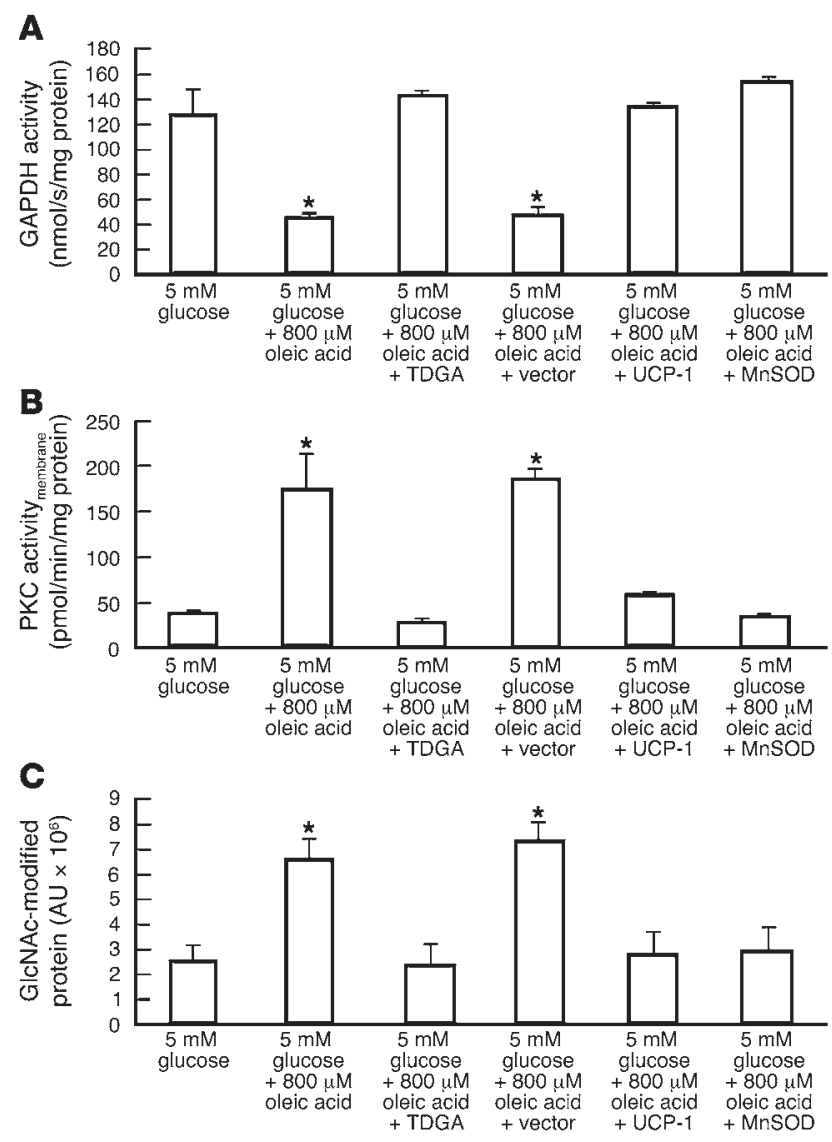

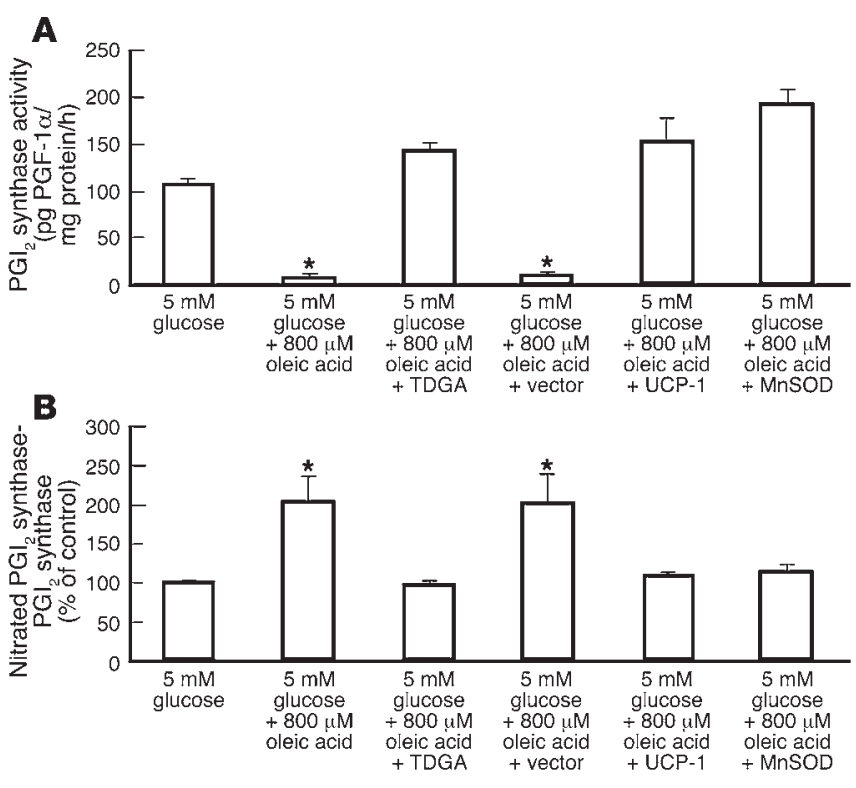

inhibition (Figure 5A, bar 3), and by overexpression of either UCP-1 or MnSOD (Figure 5A, bars 5 and 6). Consistent with these data, the degree of $\mathrm{PGI}_{2}$ tyrosine nitration at tyrosine 430 , a marker of the superoxide-derived ROS peroxynitrite (30), was increased 2-fold by $800 \mu \mathrm{M}$ oleic acid (Figure 5B, bar 2). This increase was also completely prevented by CPT-I inhibition (Figure 5B, bar 3), and by overexpression of either UCP-1 or MnSOD (Figure 5B, bars 5 and 6).

Effect of FFA-induced ROS production on eNOS activity in aortic endothelial cells. NO production by eNOS is a critical antiatherogenic defense, mediating vasodilation, inhibition of platelet activation, monocyte and leukocyte adhesion, and SMC proliferation, and inhibition of atherosclerosis in the apoE knockout mouse (23). eNOS activity is suppressed in diabetes and IR $(31,32)$. Three mechanisms have been implicated, each of which is either a downstream consequence or a direct consequence of increased ROS production, including PKC activation (19), hexosamine pathway activation (20), and oxidative uncoupling of the eNOS dimer $(21,22)$. Since FFA-induced ROS production increases ROS production, PKC activity, and hexosamine pathway activity in aortic endothelial cells, we next examined the effect of FFA-induced ROS production on eNOS activity. In cells cultured in $5 \mathrm{mM}$ glucose, $800 \mu \mathrm{M}$ oleic acid decreased eNOS activity by about 60\% (Figure 6, bar 2). eNOS protein levels did not change in the presence of oleic acid (data not shown). The inhibition was completely prevented by CPT-I inhibition (Figure 6, bar 3), and by overexpression of either UCP-1 or MnSOD (Figure 6, bars 5 and 6).

Effect of FFA infusion on $\mathrm{PGI}_{2}$ synthase activity in rat aorta. Liposyn infusion caused FFA concentrations to rise rapidly to a steadystate level of $2.275 \pm 0.176 \mathrm{mM}$, compared with a basal level of $0.379 \pm 0.034 \mathrm{mM}$. There was no change in glucose or insulin concentrations during the Liposyn infusion. This in vivo exposure of aortic endothelial cells to elevated FFA concentrations had a dramatic effect on $\mathrm{PGI}_{2}$ synthase activity, however, reducing it in the aorta by $95 \%$ (Figure 7 ).

Effect of FFA-induced ROS production on $\mathrm{PGI}_{2}$ synthase activity in $\mathrm{fa} / \mathrm{fa}$ rat aortae. In order to evaluate our hypothesis in vivo, we chose the $f a / f a$ rat as a model. These rats develop severe, early-

\section{Figure 5}

Effect of CPT-1 and ROS inhibitors on $\mathrm{PGI}_{2}$ inactivation by FFAs. (A) Effect of FFA-induced ROS production on $\mathrm{PGI}_{2}$ synthase activity. (B) Percent enzyme modified by 3-nitrotyrosine, a marker of the superoxide-derived ROS peroxynitrite. Cells were incubated in $5 \mathrm{mM}$ glucose alone or in $5 \mathrm{mM}$ glucose plus either oleic acid alone or oleic acid plus TDGA or adenoviral vectors expressing UCP-1 or MnSOD. Each bar represents the mean plus SEM of 3 separate experiments, each with $n=5$. ${ }^{*} P<0.01$ compared with cells incubated in $5 \mathrm{mM}$ glucose alone.

onset obesity associated with IR, hyperinsulinemia, and hyperleptinemia $(27,33)$. However, they maintain normal glucose tolerance (34). In addition, it has been shown that these animals have a PI3K pathway-specific IR in their arteries (14). There was no difference in fasting blood glucose levels between $\mathrm{fa} / \mathrm{fa}$ rats $(120 \pm 5 \mathrm{mg} / \mathrm{dl})$ and lean controls $(F A / f a$ [rats heterozygous for the mutant allele] or $F A / F A$ [rats homozygous for the nonmutant allele]) $(121 \pm 4 \mathrm{mg} / \mathrm{dl})$, nor in glycated hemoglobin levels (5.5\% versus $5.4 \%$ ). In aortae of $f a / f a$ rats (Figure $8 \mathrm{~A}$, bar 2 ), $\mathrm{PGI}_{2}$ synthase activity was reduced by more than $95 \%$ compared with $\mathrm{PGI}_{2}$ synthase activity in aortae from lean controls (Figure 8A, bar 1); this was similar to what was observed previously in cultured aortic endothelial cells. Administration of the superoxide dismutase (SOD) mimetic manganese (III) tetrakis(4-benzoic acid) porphyrin (MnTBAP) for 1 week normalized $\mathrm{PGI}_{2}$ synthase activity in aortae of $f a / f a$ rats (Figure $8 \mathrm{~A}$, bar 3 ), indicating that superoxide overproduction was responsible for the observed inhibition of aortic $\mathrm{PGI}_{2}$ synthase activity. To evaluate the role of increased fatty acid flux in the generation of excessive ROS, $\mathrm{fa} / \mathrm{fa}$ rats were also treated with the antilipolytic agent nicotinic acid (NA), which decreases fatty acid release from adipose cells. NA treatment also completely normalized $\mathrm{PGI}_{2}$ synthase activity in aortae of $f a / f a$ rats (Figure $8 \mathrm{~A}$, bar 4 ), suggesting that increased fatty acid flux due to IR was the source of the increased ROS that had inhibited the enzyme. However, since NA also causes changes in various lipoprotein fractions (35), another group of $\mathrm{fa} / \mathrm{fa}$ rats were treated with etomoxir, an inhibitor of the ratelimiting enzyme for long-chain fatty acid oxidation, CPT-I (36).

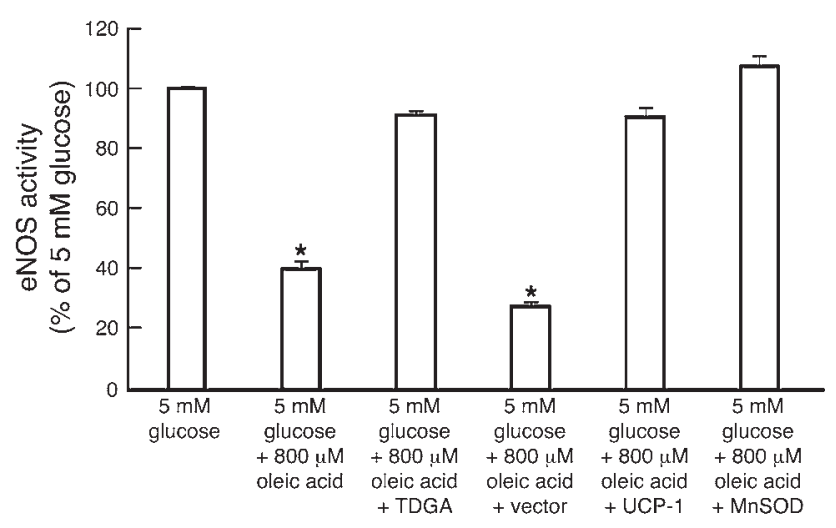

Figure 6

Effect of FFA-induced ROS production on eNOS activity in aortic endothelial cells. Cells were incubated in $5 \mathrm{mM}$ glucose alone or in $5 \mathrm{mM}$ glucose plus either oleic acid alone or oleic acid plus TDGA or adenoviral vectors expressing UCP-1 or MnSOD. Each bar represents the mean plus SEM of 3 separate experiments, each with $n=4 .{ }^{*} P<0.01$ compared with cells incubated in $5 \mathrm{mM}$ glucose alone. 


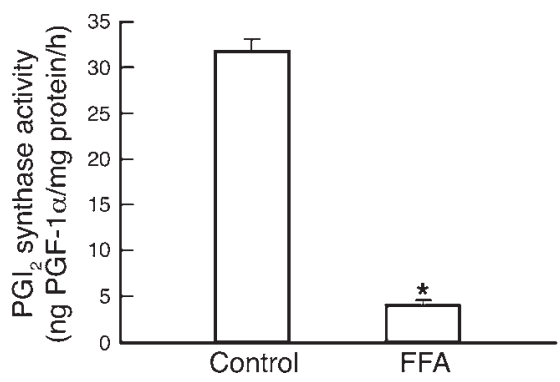

\section{Figure 7}

Effect of $\mathrm{FFA}$ infusion on $\mathrm{PGI}_{2}$ synthase activity in rat aorta. Enzyme activity was determined in control and FFA-infused rats. Each bar represents the mean plus SEM of 4 rats per group. ${ }^{*} P<0.01 \mathrm{com}$ pared with controls.

Inhibition of CPT-I restored $\mathrm{PGI}_{2}$ synthase activity in aortae of $\mathrm{fa} / \mathrm{fa}$ rats to a level that was not significantly different from control (Figure 8A, bar 5), an effect identical to that observed with CPT-I inhibition in cultured aortic endothelial cells.

Effect of FFA-induced ROS production on $\mathrm{PGI}_{2}$ synthase activity in aortae of bigh-fat diet-induced insulin-resistant mice. In order to exclude the effects of variables other than IR in the $f a / f a$ rat model, these experiments were repeated in a different model of IR, the high-fat diet-induced mouse model. In addition to being a different species, this model does not have the potentially confounding variable of the $f a / f a$ mutation in the leptin receptor. As shown in Figure 8B, the effects of FFA-induced ROS production on $\mathrm{PGI}_{2}$ synthase activity in aortae of these insulin-resistant mice were identical to those observed in the $f a / f a$ rats. $\mathrm{PGI}_{2}$ synthase activity was reduced by more than $95 \%$ (Figure $8 \mathrm{~B}$, bar 2), compared with $\mathrm{PGI}_{2}$ synthase activity in aortae from standard-diet controls (Figure 8B, bar 1). Administration of MnTBAP for 1 week normalized $\mathrm{PGI}_{2}$ synthase activity in aortae of high-fat diet-induced insulin-resistant mice (Figure 8B, bar 3), indicating that superoxide overproduction was responsible for the observed inhibition of aortic $\mathrm{PGI}_{2}$ synthase activity. To evaluate the role of increased fatty acid flux in the generation of excessive ROS, high-fat diet-induced insulin-resistant mice were also treated with the antilipolytic agent NA, which decreases fatty acid release from adipose cells. NA treatment also completely normalized $\mathrm{PGI}_{2}$ synthase activity in aortae of these insulin-resistant mice (Figure 8B, bar 4), suggesting that increased fatty acid flux due to IR was the source of the increased ROS that had inhibited the enzyme. However, since NA also causes changes in various lipoprotein fractions (35), another group of high-fat diet-induced insulin-resistant mice were treated with etomoxir, an inhibitor of the rate-limiting enzyme for long-chain fatty acid oxidation, CPT-I (36). Inhibition of CPT-I restored $\mathrm{PGI}_{2}$ synthase activity in aortae of the insulin-resistant mice to a level that was not significantly different from control (Figure 8B, bar 5).

Effect of FFA-induced ROS production on eNOS activity in fa/fa rat aortae. Identical experiments to those described above were performed to determine the effect of FFA-induced ROS production on eNOS activity. eNOS activity in aortae of $f a / f a$ rats (Figure 9A, bar 2) was reduced $78 \%$ compared with eNOS activity in aortae from lean controls (Figure 9A, bar 1). Administration of MnTBAP for 1 week normalized eNOS activity in aortae of $f a / f a$ rats (Figure 9A, bar 3), indicating that superoxide overproduction was responsible for the observed inhibition of aortic eNOS. To evaluate the role of increased fatty acid flux in the generation of excess ROS, $f a / f a$ rats were also treated with the antilipolytic agent NA, which decreases fatty acid release from adipose cells. NA treatment also completely normalized eNOS activity in aortae of $f a / f a$ rats (Figure 9B, bar 4), suggesting that increased fatty acid flux due to IR was the source of the increased ROS that inhibited the enzyme. However, since NA also causes changes in various lipoprotein fractions (35), another group of $f a / f a$ rats were treated with etomoxir, an inhibitor of the rate-limiting enzyme for long-chain fatty acid oxidation, CPT-I (36). Inhibition of CPT-I restored eNOS activity in aortae of $f a / f a$ rats to a level that was not significantly different from control (Figure 9A, bar 5), an effect identical to that observed with CPT-I inhibition in cultured aortic endothelial cells. In some cell types, etomoxir activates PPAR $\alpha$ (37), which can lead to increased eNOS transcription (38). Therefore, we determined protein levels of eNOS to confirm that effects measured in vivo were not an effect of etomoxir on eNOS expression. Our Western blot data (data not shown) showed no change in protein levels for eNOS protein and thus do not support a role for etomoxir-induced PPAR $\alpha$ activation in our cells.

Effect of FFA-induced ROS production on eNOS activity in aortae of high-fat diet-induced insulin-resistant mice. As shown in Figure 9B, the effects of FFA-induced ROS production on eNOS activity
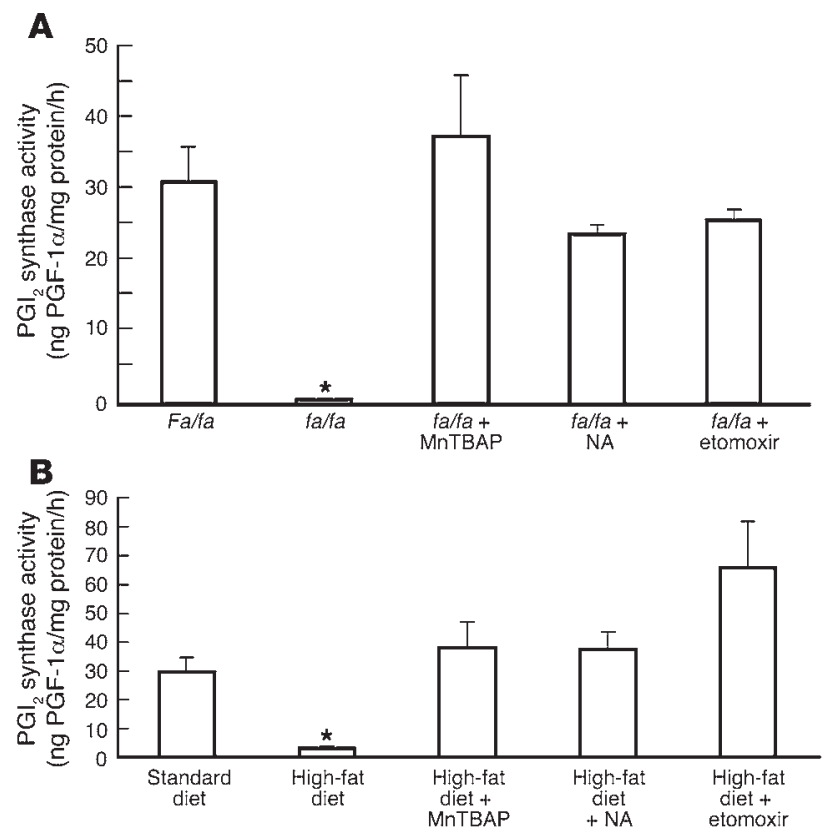

\section{Figure 8}

Effect of inhibitors of lipolysis, CPT-1, and ROS on arterial $\mathrm{PGI}_{2}$ inactivation in 2 animal models of insulin resistance. (A) Effect of FFA-induced ROS production on $\mathrm{PGI}_{2}$ synthase activity in insulin-resistant fa/fa rat aortae. Enzyme activity was determined in lean controls (FA/fa), fa/fa rats, and fa/fa rats treated with the SOD mimetic MnTBAP, the antilipolytic agent NA, or the CPT-I inhibitor etomoxir. Each bar represents the mean plus SEM of 6 rats per group. ${ }^{*} P<0.01$ compared with lean controls. (B) Effect of FFA-induced ROS production on $\mathrm{PGI}_{2}$ synthase activity in high-fat diet-induced insulin-resistant mouse aortae. Enzyme activity was determined in standard-diet controls, high-fat diet-induced insulin-resistant mice, and high-fat diet-induced insulin-resistant mice treated with the SOD mimetic MnTBAP, the antilipolytic agent NA, or the CPT-I inhibitor etomoxir. Each bar represents the mean plus SEM of 6 mice per group. ${ }^{*} P<0.01$ compared with controls. 

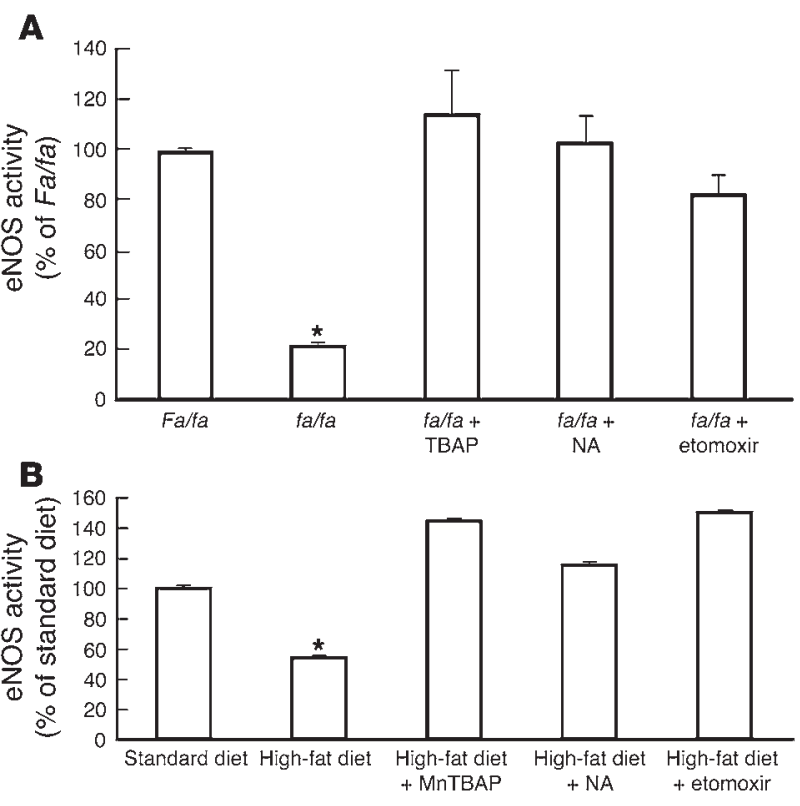

\section{Figure 9}

Effect of inhibitors of lipolysis, CPT-1, and ROS on arterial eNOS inactivation in 2 animal models of insulin resistance. (A) Effect of FFAinduced ROS production on eNOS activity in insulin-resistant fa/fa rat aortae. Enzyme activity was determined in lean controls (FA/fa), fa/fa rats, and fa/fa rats treated with the SOD mimetic MnTBAP, the antilipolytic agent NA, or the CPT-I inhibitor etomoxir. Each bar represents the mean plus SEM of 6 rats per group. ${ }^{*} P<0.01$ compared with lean controls. (B) Effect of FFA-induced ROS production on eNOS activity in high-fat diet-induced insulin-resistant mouse aortae. Enzyme activity was determined in standard-diet controls, high-fat diet-induced insulin-resistant mice, and high-fat diet-induced insulin-resistant mice treated with the SOD mimetic MnTBAP, the antilipolytic agent NA, or the CPT-I inhibitor etomoxir. Each bar represents the mean plus SEM of 6 mice per group. ${ }^{*} P<0.01$ compared with controls.

in aortae of these insulin-resistant mice were identical to those observed in the $\mathrm{fa} / \mathrm{fa}$ rats. eNOS activity was reduced by $47 \%$ (Figure 9B, bar 2), compared with eNOS activity in aortae from standard-diet controls (Figure 9B, bar 1). Administration of the SOD mimetic MnTBAP for 1 week normalized eNOS activity in aortae of high-fat diet-induced insulin-resistant mice (Figure 9B, bar 3), indicating that superoxide overproduction was responsible for the observed inhibition of aortic eNOS activity. To evaluate the role of increased fatty acid flux in the generation of excessive ROS, high-fat diet-induced insulinresistant mice were also treated with the antilipolytic agent NA, which decreases fatty acid release from adipose cells. NA treatment also completely normalized eNOS synthase activity in aortae of these insulin-resistant mice (Figure 9B, bar 4), suggesting that increased fatty acid flux due to IR was the source of the increased ROS that had inhibited the enzyme. However, since NA also causes changes in various lipoprotein fractions (35), another group of high-fat diet-induced insulin-resistant mice were treated with etomoxir, an inhibitor of the rate-limiting enzyme for long-chain fatty acid oxidation, CPT-I (36). Inhibition of CPT-I restored eNOS activity in aortae of the insulin-resistant mice to a level that was not significantly different from control (Figure 9B, bar 5).

\section{Discussion}

In this report, we show that levels of FFA commonly seen in people with IR cause increased production of superoxide in arterial endothelial cells cultured in $5 \mathrm{mM}$ glucose without insulin, by providing increased electron donors (NADH and $\mathrm{FADH}_{2}$ ) to the mitochondrial electron transport chain. The metabolic pathways we studied in our arterial endothelial cell model are regulated by insulin signaling under physiologic conditions. Therefore, in our cell culture experiments, we used a lack of insulin as a model for IR in these cells. Although several studies have claimed that fatty acids increase ROS production $(39,40)$, the albumin concentrations used to bind the fatty acids were so low that the relevance of these observations to fatty acid metabolism in human disease is uncertain. In our experiments, we used $1,000 \mu \mathrm{M}$ of fatty acid-free albumin, a concentration somewhat higher than the normal range (530-833 $\mu \mathrm{M})$, to ensure that the FFA fraction (the fraction unbound to albumin) would be similar to that found in insulin-resistant humans. The FFA-induced overproduction of superoxide activates a variety of proinflammatory signals previously implicated in hyperglycemia-induced vascular damage and inactivates 2 critically important antiatherogenic enzymes, $\mathrm{PGI}_{2}$ synthase and eNOS $(23,24)$.

It has been reported that atherosclerosis is accelerated in transgenic mice overexpressing eNOS, in association with increased oxidative stress (41). These results, however, are consistent with our hypothesis that increased superoxide formation promotes vascular damage. It is well documented that when levels of substrate (arginine) and/or cofactor (tetrahydrobiopterin) needed for NO synthesis are insufficient relative to the amount of eNOS protein, eNOS becomes uncoupled and produces superoxide, rather than NO (42). This appears to be the case in these transgenic mice.

Our animal models, like other animal models and indeed humans, require the presence of significant hypercholesterolemia in order to develop atherosclerotic lesions (43). Only with significant hypercholesterolemia caused by genetic and dietary manipulations do any established atherosclerosis risk factors lead to arterial lesions. We did not cross our animal models of IR with animals having genetic mutations causing the dyslipidemia necessary to produce atherosclerosis. However, when knockout mice with reduced $\mathrm{PGI}_{2}$ synthase activity or reduced eNOS activity, similar to that observed in our insulin-resistant models, were crossed with mice that do have genetic mutations (apoE-null) that cause dyslipidemia, they both developed significantly worse atherosclerosis (23).

Finally, in our study, infusion of FFA dramatically inhibited aortic $\mathrm{PGI}_{2}$ synthase activity in nondiabetic rats. In 2 widely accepted nondiabetic rodent models of IR, the fa/fa rat and the high-fat dietinduced insulin-resistant mouse, inactivation of $\mathrm{PGI}_{2}$ synthase and eNOS was prevented by inhibition of FFA release from adipose tissue; by inhibition of the rate-limiting enzyme for fatty acid oxidation in mitochondria, CPT-I; and by reduction of superoxide levels.

Consistent with these data, short-term FFA infusions significantly reduce eNOS-dependent vasodilation in lean, normal, insulin-sensitive human subjects (44). FFAs have also been shown to induce IR in nondiabetic subjects (45), and IR is known to increase FFA release from adipocytes. These data suggest that a positive feed-forward cycle, between increased FFA flux and IR, may sustain or even augment FFA-induced vascular endothelial dysfunction.

In both animal models used in our studies, increased FFA flux is thought to play a major role in the development of IR (46). 
However, it is likely that alterations in non-fatty acid adipocyte secretory products such as adiponectin, resistin, TNF- $\alpha$, and retinol-binding protein 4 play a role as well $(47,48)$. Furthermore, IR and obesity are accompanied by high levels of circulating leptin. Leptin induces increased ROS production in aortic endothelial cells, by inducing increased fatty acid oxidation through stimulation of CPT-I and inhibition of acetyl-CoA carboxylase (49). Besides this induction of increased ROS production, leptin has also been shown to exert other proinflammatory actions (50). Therefore, in order to separate the leptin-induced proinflammatory effects from those potentially induced by IR, we chose one of our animal models of IR, the $f a / f a$ rat, to be a model with leptin deficiency. The $f a / f a$ rat carries a loss-of-function mutation in the leptin receptor, a single-nucleotide substitution that results in an amino acid change from glutamine to proline at codon 269 in the extracellular domain of the leptin receptor, which impairs leptin signaling through JAK2 and STAT3 (51). Since activated JAK2 phosphorylates insulin receptor substrate (IRS) proteins, which subsequently recruit PI3K and downstream mediators of insulin action in adipocytes, impaired adipocyte insulin signaling increases FFA release in this model. The increased FFA flux induces IR by increasing intracellular accumulation of fatty acid metabolites such as diacylglycerol, fatty acyl-CoA, and ceramides, which desensitize insulin signaling by increasing IRS serine/threonine phosphorylation, and also by activating $S 6$ kinase 1 , an effector of the mammalian target of rapamycin (mTOR) (52-55).

In the high-fat diet-induced insulin-resistant mouse, excess dietary fatty acids and glucose are thought to cause desensitization of insulin signaling through increased IRS1 serine/threonine phosphorylation by these same mechanisms.

Although the focus of the present study is on the proatherogenic effects of IR in nondiabetic animals, the further increase in CVD in patients with IR plus diabetes (56-58) raises the question of metabolic interactions between fatty acids and glucose in arterial endothelial cells (54). The concentrations of fatty acid used in the experiments $(800 \mu \mathrm{M})$ caused a reduction in glucose flux through the TCA cycle of $40 \%$ at $30 \mathrm{mM}$ glucose. However, this was still 3.7-fold higher than glucose flux at $5 \mathrm{mM}$ glucose. What about the effect of increased glucose oxidation on the rate of fatty acid oxidation by arterial endothelial cells? Normally, glucose oxidation inhibits both lipolysis and fatty acid oxidation. Both of these effects are mediated predominantly by insulin (59). In adipocytes, insulin-stimulated glycolysis increases the availability of glycerol phosphate, the rate-limiting metabolite for FFA reesterification. In tissues oxidizing both glucose and fatty acids, increased insulin concentrations in response to glucose inhibit long-chain fatty acid entrance into the mitochondria by increasing malonyl-CoA formation, which inhibits CPT-I activity.

However, since hyperglycemia impairs activation of the IR/IRS/PI3K pathway in both adipocytes (60) and human arterial endothelial cells (61), the inhibitory effects of hyperglycemia on both the rate of FFA release by adipocytes and the rate of FFA oxidation by arterial endothelial cells are likely to be considerably reduced. It seems probable, therefore, that the effects of IR and hyperglycemia on arterial endothelial cells are additive, since oxidation of both FFA and glucose causes overproduction of superoxide by the mitochondrial electron transport chain in these cells $(10,12)$.

Our studies on the effect of FFAs were performed using oleic acid. The fatty acids found in the human circulation are mainly palmitic acid, oleic acid, and stearic acid. It has been suggested that the toxic effects of palmitic acid differ from those of oleic (62). Therefore, we also tested palmitic acid in our BAEC model of IR. ROS production in response to palmitic acid exposure increased in a dose-responsive manner as well (data not shown).

While hyperglycemia increases overproduction of superoxide by the mitochondrial electron transport chain in both arterial endothelial cells and retinal microvascular endothelial cells, it was surprising to find that FFA increases superoxide production only in arterial endothelial cells. It is known from global expression profiling studies that pervasive differences in gene expression patterns distinguish macrovascular from microvascular endothelial cells (63). Regardless of which differences account for the differential effects of FFA on these 2 endothelial cell types, our finding is consistent with the lack of diabetic microvascular complications in people with significant IR but normal glucose tolerance.

In summary, our studies identify what we believe to be a novel mechanism contributing to the accelerated atherogenesis and increased CVD risk occurring in people with IR, independent of other known cardiovascular risk factors: increased fatty acid oxidation-induced superoxide production by arterial endothelial cells. Our finding that inhibitors of lipolysis, inhibitors of CPT-I, and SOD mimetics can each prevent proatherogenic changes induced by IR in arterial endothelium in vivo suggests novel pharmacologic approaches for reducing CVD in patients with IR.

\section{Methods}

Materials. MEM, nonessential amino acids, and antibiotics were from Invitrogen Corp. FBS was from HyClone. MnTBAP was from Calbiochem. Protein A-Sepharose was from Amersham Pharmacia Biotech. Oleic acid, pure fatty acid-free albumin, and NA were from Sigma-Aldrich; CM-H2DCFDA was from Invitrogen Corp. TDGA was a gift from Manuel Guzman (Complutense University, Madrid, Spain). Six-keto-PGF-1 $\alpha$ kits were obtained from Assay Designs. Nitrotyrosine antibody was obtained from Upstate. ALZET pumps were obtained from DURECT Corp. FFA kits were purchased from Wako Pure Chemicals Industries Ltd.

Cell culture conditions. As a cell culture model of IR, confluent BAECs (passages 4-10) were maintained in MEM containing 0.4\% FBS, essential and nonessential amino acids, and antibiotics, without added insulin except where indicated. Cells were incubated with either $5 \mathrm{mM}$ glucose; $5 \mathrm{mM}$ glucose plus $1 \mathrm{mM}$ albumin plus $200-800 \mu \mathrm{M}$ oleic acid; or $5 \mathrm{mM}$ glucose plus $1 \mathrm{mM}$ albumin plus $800 \mu \mathrm{M}$ oleic acid plus $3 \mathrm{nM}$ insulin, with and without pretreatment with $100 \mathrm{nM}$ wortmannin for 30 minutes. In subsequent experiments, cells were incubated in $5 \mathrm{mM}$ glucose plus $1 \mathrm{mM}$ albumin plus $800 \mu \mathrm{M}$ oleic acid plus TDGA, or they were infected with UCP-1 adenovirus, MnSOD adenovirus, or control adenovirus 48 hours before addition of $1 \mathrm{mM}$ albumin plus $800 \mu \mathrm{M}$ oleic acid-containing medium. Cells were incubated for 6 hours before determination of ROS, 72 hours before determination of PKC activity, 48 hours before determination of hexosamine pathway activity, and 24 hours before determination of GAPDH, $\mathrm{PGI}_{2}$, and eNOS activity. Bovine retinal endothelial cells (BRECs) were obtained from VEC Technologies Inc. BRECs were plated on fibronectin-coated plates and maintained in MCDB-131 complete media provided by the company.

Adenoviral vectors. Rat UCP-1 sense and antisense cDNAs were provided by D. Ricquier (CNRS-Unité Propre 1511, Meudon, France), and human MnSOD cDNA was provided by L. Oberley (University of Iowa College of Medicine, Iowa City, Iowa, USA). The cDNAs were cloned into the shuttle vector pAd5CMVK-NpA, and adenoviral vectors were prepared by the Gene Transfer Vector Core at the University of Iowa. Cells were infected at an MOI of 500 for 2 hours. 
ROS quantitation. Cells were plated in a 96-well cell culture plate at a density to obtain confluence. Twenty-four hours after plating, the cells were cultured for 6 hours using the treatments described above. The intracellular formation of ROS was detected using the fluorescent probe CM-H2DCFDA (Invitrogen Corp.). Cells were loaded with $10 \mu \mathrm{M}$ CM-H2DCFDA, incubated for 45 minutes at $37^{\circ} \mathrm{C}$, and analyzed with an HTS 7000 Bio Assay Fluorescent Plate Reader (PerkinElmer) using the HTSoft software program (HTS 700 Bio Assay Fluorescent plate reader; PerkinElmer) (10).

GAPDH activity. BAECs were grown to confluence, harvested using trypsin-EDTA after washing twice with PBS, and resuspended in lysis buffer. The cytosolic fraction was prepared by centrifugation of the lysate at $100,000 \mathrm{~g}$ at $4^{\circ} \mathrm{C}$ for 30 minutes. Protein was measured using the Pierce Coomassie Plus reagent (Pierce). GAPDH activity was determined as described previously $(64,65)$.

PKC activity. The assay was performed according to the manufacturer's instructions using the Protein Kinase C Assay System (Invitrogen Corp.).

Hexosamine pathway activity. Hexosamine pathway activity was assessed by measurement of UDP- $N$-acetylglucosamine concentration. Cells were homogenized in 3 volumes $(600 \mu \mathrm{l}$ ) of cold $0.6 \mathrm{M}$ perchloric acid and kept at $0{ }^{\circ} \mathrm{C}$ for 10 minutes. The precipitated proteins were removed by centrifugation for 5 minutes at $13,500 \mathrm{~g}$, and UDP- $\mathrm{N}$-acetylglucosamine in the supernatant was determined by HPLC as previously described (64).

Prostacylcin synthase activity. Activity was measured by determination of 6-keto-PGF-1 $\alpha$, a stable product produced by the nonenzymatic hydration of $\mathrm{PGI}_{2}$. A competitive immunoassay method (Correlate-EIA) was used for the quantitative determination of 6 -keto-PGF- $1 \alpha$, according to the manufacturer's instructions (Assay Designs). For 6-keto-PGF-1 $\alpha$ determination in rat aortae, the aortae were dissected from the abdominal bifurcation to the aortic arch. The aortae were washed with PBS and incubated at $37^{\circ} \mathrm{C}$ for 3 hours in $400 \mu$ incubation buffer.

Determination of 3-nitrotyrosine-modified prostacylcin synthase. BAECs were plated in 100-mm cell culture plates and grown to confluence. Cells $\left(2 \times 10^{7}\right)$ were scraped from the plates, pelleted, and washed twice with cold PBS. The pellet was resuspended in $0.5 \mathrm{ml}$ cold lysis buffer $(50 \mathrm{mM}$ Tris- $\mathrm{HCl}$ [pH 7.6], 1\% NP-40, 0.25\% Na-deoxycholate, $150 \mathrm{mM} \mathrm{NaCl}, 1 \mathrm{mM}$ EDTA, $1 \mathrm{mM}$ PMSF, aprotinin, leupeptin, pepstatin, $1 \mathrm{mM} \mathrm{Na}_{3} \mathrm{VO}_{4}$, and $1 \mathrm{mM}$ $\mathrm{NaF}$ ), and incubated on ice for 30 minutes. Cellular debris was pelleted for 20 minutes at $20,000 \mathrm{~g}$ at $4^{\circ} \mathrm{C}$. Five hundred micrograms of protein was immunoprecipitated with $4 \mu \mathrm{g}$ of 3 -nitrotyrosine antibody (rabbit polyclonal; Upstate), and $20 \mu$ l of protein A-agarose in PBS. Samples were rotated overnight at $4{ }^{\circ} \mathrm{C}$, and the immunoprecipitated complexes were pelleted by centrifugation $(10,000 \mathrm{~g})$ and washed $4-5$ times with PBS. The pellet was resuspended in $1 \times$ sample buffer, boiled, and analyzed by $7.5 \%$ SDS-PAGE (20) with Western blotting for $\mathrm{PGI}_{2}$ synthase.

Western blotting. Immunoprecipitated proteins electrophoresed on $10 \%$ PAGE gels were transferred onto nitrocellulose membranes. The immunoblots were developed with 1:1,000 dilutions of antibody, and the signal was detected with the ECF system according to the manufacturer's instructions (Amersham Pharmacia Biotech). The images were scanned into a Molecular Dynamics FluorImager and analyzed using the ImageQuant 5.5 program (Amersham Pharmacia Biotech).

eNOS activity. eNOS activity in cells was determined as previously described (66). Activity of eNOS in cell lysates and tissue was also determined by a previously described immunoprecipitation assay (67). Samples were split into 2 tubes, 1 for Western blotting and 1 for determination of eNOS activity. eNOS immunocomplexes immobilized on protein A-Sepharose beads were resuspended in assay buffer, and eNOS activity was determined by measurement of the conversion of $\left[{ }^{3} \mathrm{H}\right] \mathrm{L}$-arginine into $\left[{ }^{3} \mathrm{H}\right] \mathrm{L}$-citrulline. All enzyme activities were corrected for $\left[{ }^{3} \mathrm{H}\right] \mathrm{L}$-arginine uptake into the cells under the various experimental conditions, determined using a previously described method (68).
Animals. For the fatty acid infusion experiments, nondiabetic male Sprague-Dawley rats were obtained from Charles River Laboratories. All procedures were performed in accordance with the Guide for Care and Use of Laboratory Animals of the NIH and were approved by the Animal Subjects Committee of the Albert Einstein College of Medicine. Hyperinsulinemic-euglycemic clamps with fatty acid infusion were performed as described previously, using a heparinized $10 \%$ triglyceride emulsion (Liposyn; Abbott Laboratories) infused at a rate of $1.5 \mathrm{ml} / \mathrm{h}$ for a period of 3 hours after a basal period of 2 hours (69). After terminal blood sampling, animals were killed with a lethal dose of sodium pentobarbital $(100 \mathrm{mg} / \mathrm{kg}$; Nembutal; Abbott Laboratories), and aortae were excised and immediately used for determination of $\mathrm{PGI}_{2}$ synthase activity.

For experiments with insulin-resistant rats, 9-week-old male Zucker $f a / f a$ (fatty) rats and their lean $F A / f a$ controls were obtained from Charles River Laboratories. An ALZET osmotic pump containing 3.5 M NA was surgically placed under the skin of a group of $f a / f a$ rats. The pump delivered NA at a rate of $10 \mu \mathrm{l} / \mathrm{h}$ for 7 days. Another group of $f a / f a$ rats was given a daily i.p. injection of MnTBAP at a dose of $10 \mathrm{mg} / \mathrm{kg}$ for 7 days. A separate group of $f a / f a$ rats was given a daily i.p. injection of etomoxir at a dose of $18 \mathrm{mg} / \mathrm{kg}$ for 7 days. After 7 days the rats were anesthetized and bled from the orbital sinus. The aortae were removed and used for $\mathrm{PGI}_{2}$ synthase and determination of eNOS activity.

For experiments with high-fat diet-induced insulin-resistant mice, 8-week-old male C57BL/ 6 mice were obtained from Charles River Laboratories. Animals were placed on a high-fat diet containing $60 \% \mathrm{kcal}$ from fat $(28,29)$.

The high-fat diet was obtained from Research Diets Inc. and was stored in the cold. Body weight was monitored every 2 weeks. Plasma insulin was determined by RIA at 7 weeks and again at 14 weeks. Experiments were performed after $15-16$ weeks on the diet. Animals were randomized into 5 groups with equivalent insulin levels (control, $0.44 \pm 0.16 \mathrm{ng} / \mathrm{ml}$; high-fat diet alone, $5.95 \pm 0.95 \mathrm{ng} / \mathrm{ml}$; high-fat diet plus etomoxir, $5.93 \pm 1.12 \mathrm{ng} / \mathrm{ml}$; high-fat diet plus NA, $5.32 \pm 0.62 \mathrm{ng} / \mathrm{ml}$; high-fat diet plus MnTBAP, $6.19 \pm 0.96 \mathrm{ng} / \mathrm{ml}$ ). An ALZET osmotic pump containing $3.5 \mathrm{M}$ NA was surgically placed under the skin of one group of high-fat-fed mice. The pump delivered NA at a rate of $0.5 \mu \mathrm{l} / \mathrm{h}$ for 7 days. Another group of mice was given a daily i.p. injection of MnTBAP, at a dose of $10 \mathrm{mg} / \mathrm{kg}$, for 7 days. A third group of mice was given a daily i.p. injection of etomoxir at a dose of $9 \mathrm{mg} / \mathrm{kg}$ for 7 days. The fourth group served as the high-fat diet-induced IR controls. After 7 days the mice were anesthetized and bled from the orbital sinus. The plasma was collected and nonesterified FFAs determined. The aorta was removed and used for $\mathrm{PGI}_{2}$ synthase and eNOS activity assays as described above.

FFA determination. Plasma FFA levels were measured enzymatically using a commercially available kit (Nonesterified Fatty Acid Calibrator kit; Wako Pure Chemicals Industries Ltd.).

Insulin determination. Insulin levels were determined by an RIA using iodinated human insulin (Amersham Pharmacia Biotech), rat insulin as a standard (Linco Research Inc.), and PBS containing 0.1\% BSA as assay buffer (70).

Statistics. Data were analyzed using 1-factor ANOVA to compare the means of all the groups. The Tukey-Kramer multiple-comparisons procedure was used to determine which pairs of means were different. $P$ values less than 0.01 were considered statistically significant.

\section{Acknowledgments}

This work was supported in part by NIH grant P01 AG021654, by Diabetes Research and Training Center grant DK20541-27 (to the Albert Einstein College of Medicine), and by a generous gift from Guy and Marcia Struve. We appreciate expert advice from Dan Stein about fatty acids for cell culture, and from Jon 
Backer about PI3K. We are also grateful for the friendship and support of the late Denis McGarry.

Received for publication September 14, 2004, and accepted in revised form January 5, 2006.

1. Bonora, E., et al. 1988. Prevalence of IR in metabolic disorders: the Bruneck Study. Diabetes. 47:1643-1649

2. Haffner, S.M., Lehto, S., Ronnemaa, T., Pyorala, K., and Laakso, M. 1998. Mortality from coronary heart disease in subjects with type 2 diabetes and in nondiabetic subjects with and without prior myocardial infarction. N. Engl. J. Med. 339:229-234.

3. Saydah, S.H., et al. 2001. Postchallenge hyperglycemia and mortality in a national sample of U.S. adults. Diabetes Care. 24:1397-1402.

4. National Diabetes Data Group. 1995. Diabetes in America. 2nd edition. National Institute of Diabetes and Digestive and Kidney Diseases, NIH. Bethesda, Maryland, USA. 782 pp.

5. DECODE Study Group, the European Diabetes Epidemiology Group. 2001. Glucose tolerance and cardiovascular mortality: comparison of fasting and 2-hour diagnostic criteria. Arch. Intern. Med. 161:397-405.

6. Yip, J., Facchini, F.S., and Reaven, G.M. 1998. Resistance to insulin-mediated glucose disposal as a predictor of cardiovascular disease. J. Clin. Endocrinol. Metab. 83:2773-2776.

7. Hanley, A.J., Williams, K., Stern, M.P., and Haffner, S.M. 2002. Homeostasis model assessment of IR in relation to the incidence of cardiovascular disease: the San Antonio Heart Study. Diabetes Care. 25:1177-1184.

8. Shimomura, I., et al. 1999. Insulin selectively increases SREBP-1c mRNA in the livers of rats with streptozotocin-induced diabetes. Proc. Natl. Acad. Sci. U. S. A. 23:13656-13661.

9. Chen, G., Liang, G., Ou, J., Goldstein, J.L., and Brown, M.S. 2004. Central role for liver X receptor in insulin-mediated activation of Srebp-1c transcription and stimulation of fatty acid synthesis in liver. Proc. Natl. Acad. Sci. U. S. A. 101:11245-11250.

10. Nishikawa, T., et al. 2000. Normalizing mitochondrial superoxide production blocks three pathways of hyperglycaemic damage. Nature. 404:787-790.

11. Brownlee, M. 2001. Biochemistry and molecular cell biology of diabetic complications. Nature. 414:813-820.

12. Du, X., et al. 2003. Inhibition of GAPDH activity by poly (ADP-ribose) polymerase activates three major pathways of hyperglycemic damage. J. Clin. Invest. 112:1049-1057. doi:10.1172/JCI200318127.

13. Manganiello, V.C., Degerman, E., Taira, M., Kono, T., and Belfrage, P. 1996. Type III cyclic nucleotide phosphodiesterases and insulin action. Curr. Top. Cell. Regul. 34:63-100.

14. Jiang, Z.Y., et al. 1999. Characterization of selective resistance to insulin signaling in the vasculature of obese Zucker ( $\mathrm{fa} / \mathrm{fa}$ ) rats. J. Clin. Invest. 104:447-457.

15. Moule, S.K., and Denton, R.M. 1997. Multiple signaling pathways involved in the metabolic effects of insulin. Am. J. Cardiol. 80:41A-49A.

16. Schmidt, A.M., et al. 1995. Advanced glycation endproducts interacting with their endothelial receptor induce expression of vascular cell adhesion molecule-1 (VCAM-1) in cultured human endothelial cells and in mice. A potential mechanism for the accelerated vasculopathy of diabetes. J. Clin. Invest. 96:1395-1403.

17. Zou, M.H., Shi, C., and Cohen, R.A. 2002. High glucose via peroxynitrite causes tyrosine nitration and inactivation of prostacyclin synthase that is associated with thromboxane/prostaglandin $\mathrm{H}(2)$ receptormediated apoptosis and adhesion molecule expression in cultured human aortic endothelial cells.
Address correspondence to: Michael Brownlee, Diabetes Research Center, Albert Einstein College of Medicine, 1300 Morris Park Avenue, Bronx, New York 10461, USA. Phone: (718) 430-3636; Fax: (718) 430-8570; E-mail: brownlee@aecom.yu.edu.
Diabetes. 51:198-203.

18. de Leval, X., et al. 2004. New developments on thromboxane and prostacyclin modulators part II: prostacyclin modulators. Curr. Med. Chem. 11:1243-1252.

19. Kuboki, K., et al. 2000. Regulation of endothelial constitutive nitric oxide synthase gene expression in endothelial cells and in vivo: a specific vascular action of insulin. Circulation. 101:676-681.

20. Du, X.L., et al. 2001. Hyperglycemia inhibits endothelial nitric oxide synthase activity by posttranslational modification at the Akt site. J. Clin. Invest. 108:1341-1348. doi:10.1172/JCI200111235.

21. Zou, M.H., Shi, C., and Cohen, R.A. 2002. Oxidation of the zinc-thiolate complex and uncoupling of endothelial nitric oxide synthase by peroxynitrite. J. Clin. Invest. 109:817-826. doi:10.1172/ JCI200214442.

22. de Nigris, F., et al. 2003. Beneficial effects of antioxidants and L-arginine on oxidation-sensitive gene expression and endothelial NO synthase activity at sites of disturbed shear stress. Proc. Natl. Acad. Sci. U. S. A. 100:1420-1425.

23. Kuhlencordt, P.J., et al. 2001. Accelerated atherosclerosis, aortic aneurysm formation, and ischemic heart disease in apolipoprotein $\mathrm{E} /$ endothelial nitric oxide synthase double-knockout mice. Circulation. 104:448-454

24. Kobayashi, T., et al. 2004. Roles of thromboxane $\mathrm{A}(2)$ and prostacyclin in the development of atherosclerosis in apoE-deficient mice. J. Clin. Invest. 114:784-794. doi:10.1172/JCI200421446.

25. Heitzer, T., Schlinzig, T., Krohn, K., Meinertz, T., and Munzel, T. 2001. Endothelial dysfunction, oxidative stress, and risk of cardiovascular events in patients with coronary artery disease. Circulation. 104:2673-2678.

26. Schachinger, V., Britten, M.B., and Zeiher, A.M. 2000. Prognostic impact of coronary vasodilator dysfunction on adverse long-term outcome of coronary heart disease. Circulation. 101:1899-1906.

27. Bray, G.A. 1977. The Zucker-fatty rat: a review. Fed. Proc. 36:148-153.

28. Rossmeisl, M., Rim, J.S., Koza, R.A., and Kozak, L.P. 2003. Variation in type 2 diabetes-related traits in mouse strains susceptible to diet-induced obesity. Diabetes. 52:1958-1966.

29. Conarello, S.L., et al. 2003. Mice lacking dipeptidyl peptidase IV are protected against obesity and IR Proc. Natl. Acad. Sci. U. S. A. 100:6825-6830.

30. Schmidt, P., et al. 2003. Specific nitration at tyrosine 430 revealed by high resolution mass spectrometry as basis for redox regulation of bovine prostacyclin synthase. J. Biol. Chem. 278:12813-12819.

31. Granger, C.B., et al. 1993. Outcome of patients with diabetes mellitus and acute myocardial infarction treated with thrombolytic agents. The Thrombolysis and Angioplasty in Myocardial Infarction (TAMI) Study Group. J. Am. Coll. Cardiol. 21:920-925.

32. Frisbee, J.C., and Stepp, D.W. 2001. Impaired NOdependent dilation of skeletal muscle arterioles in hypertensive diabetic obese Zucker rats. Am. J. Physiol. Heart Circ. Physiol. 281:H1304-H1311.

33. Iida, M., et al. 1996. Substitution at codon 269 (glutamine -> proline) of the leptin receptor (OBR) CDNA is the only mutation found in the Zucker fatty $(f a / f a)$ rat. Biochem. Biophys. Res. Commun. 224:597-604

34. Amy, R.M., Dolphin, P.J., Pederson, R.A., and Russell, J.C. 1988. Atherogenesis in two strains of obese rats. The fatty Zucker and LA/N-corpulent. Atherosclerosis. 69:199-209.
35. McKenney, J. 2004. New perspectives on the use of niacin in the treatment of lipid disorders. Arch. Intern. Med. 164:697-705.

36. Zarain-Herzberg, A., and Rupp, H. 2002. Therapeutic potential of CPT I inhibitors: cardiac gene transcription as a target. Expert Opin. Investig. Drugs. 11:345-356.

37. Djouadi, F., et al. 1998. A gender-related defect in lipid metabolism and glucose homeostasis in peroxisome proliferator-activated receptor $\alpha$-deficient mice. J. Clin. Invest. 102:1083-1091.

38. Goya, K., et al. 2004. Peroxisome proliferator-activated receptor alpha agonists increase nitric oxide synthase expression in vascular endothelial cells. Arterioscler. Thromb. Vasc. Biol. 24:658-663.

39. Inoguchi, T., et al. 2000. High glucose level and free fatty acid stimulate reactive oxygen species production through protein kinase $\mathrm{C}$-dependent activation of NAD $(\mathrm{P}) \mathrm{H}$ oxidase in cultured vascular cells. Diabetes. 49:1939-1945.

40. Furukawa, S., et al. 2004. Increased oxidative stress in obesity and its impact on metabolic syndrome. J. Clin. Invest. 114:1752-1761. doi:10.1172/ JCI200421625.

41. Ozaki, M., et al. 2002. Overexpression of endothelial nitric oxide synthase accelerates atherosclerotic lesion formation in apoE-deficient mice. J. Clin. Invest. 110:331-340. doi:10.1172/JCI200215215.

42. Alp, N.J., and Channon, K.M. 2004. Regulation of endothelial nitric oxide synthase by tetrahydrobiopterin in vascular disease. Arterioscler. Thromb. Vasc. Biol. 24:413-420.

43. Glass, C.K., and Witztum, J.L. 2001. Atherosclerosis: the road ahead. Cell. 104:503-516.

44. Steinberg, H.O., et al. 1997. Elevated circulating free fatty acid levels impair endothelium-dependent vasodilation. J. Clin. Invest. 100:1230-1239.

45. Boden, G., Chen, X., Ruiz, J., White, J.V., and Rossetti, L. 1994. Mechanisms of fatty acid-induced inhibition of glucose uptake. J. Clin. Invest. 93:2438-2446.

46. Liu, R.H., Mizuta, M., Kurose, T., and Matsukura, S. 2002. Early events involved in the development of IR in Zucker fatty rat. Int. J. Obes. Relat. Metab. Disord. 26:318-326.

47. Nawrocki, A.R., and Scherer, P.E. 2004. The delicate balance between fat and muscle: adipokines in metabolic disease and musculoskeletal inflammation. Curr. Opin. Pharmacol. 4:281-289.

48. Yang, Q., et al. 2005. Serum retinol binding protein 4 contributes to IR in obesity and type 2 diabetes. Nature. 436:356-362.

49. Yamagishi, S.I., et al. 2001. Leptin induces mitochondrial superoxide production and monocyte chemoattractant protein-1 expression in aortic endothelial cells by increasing fatty acid oxidation via protein kinase A. J. Biol. Chem. 276:25096-25100.

50. La Cava, A., and Matarese, G. 2004. The weight of leptin in immunity. Nat. Rev. Immunol. 4:371-379.

51. da Silva, B.A., Bjorbaek, C., Uotani, S., and Flier, J.S. 1998. Functional properties of leptin receptor isoforms containing the gln--> pro extracellular domain mutation of the fatty rat. Endocrinology. 139:3681-3689.

52. Munzberg, H., and Myers, M.G., Jr. 2005. Molecular and anatomical determinants of central leptin resistance. Nat. Neurosci. 8:566-570.

53. Um, S.H., et al. 2004. Absence of S6K1 protects against age- and diet-induced obesity while enhancing insulin sensitivity. Nature. 431:200-205.

54. Schulman, G.I. 2000. Cellular mechanisms of IR. J. Clin. Invest. 106:171-176. 
55. Unger, R.H., and Orci, L. 2001. Diseases of liporegulation: new perspective on obesity and related disorders. FASEB J. 15:312-321.

56. Krolewski, A.S., et al. 1987. Magnitude and determinants of coronary artery disease in juvenile-onset, insulin-dependent diabetes mellitus. Am. J. Cardiol. 59:750-755.

57. Larsen, J., et al. 2002. Silent coronary atheromatosis in type 1 diabetic patients and its relation to longterm glycemic control. Diabetes. 51:2637-2641.

58. Stamler, J., Vaccaro, O., Neaton, J.D., and Wentworth, D. 1993. Diabetes, other risk factors, and 12 -yr cardiovascular mortality for men screened in the Multiple Risk Factor Intervention Trial. Diabetes Care. 16:434-444.

59. Wolfe, R.R. 1998. Metabolic interactions between glucose and fatty acids in humans. Am. J. Clin. Nutr. 67(Suppl. 3):519S-526S.

60. Lin, Y., et al. 2005. The hyperglycemia-induced inflammatory response in adipocytes: the role of reactive oxygen species. J. Biol. Chem. 280:4617-4626.
61. Federici, M., et al. 2002. Insulin-dependent activation of endothelial nitric oxide synthase is impaired by O-linked glycosylation modification of signaling proteins in human coronary endothelial cells. Circulation. 106:466-472.

62. Listenberger, L.L., et al. 2003. Triglyceride accumulation protects against fatty acid-induced lipotoxicity. Proc. Natl. Acad. Sci. U. S. A. 100:3077-3082.

63. Chi, J.T., et al. 2003. Endothelial cell diversity revealed by global expression profiling. Proc. Natl. Acad. Sci. U. S. A. 100:10623-10628.

64. Du, X.L., et al. 2000. Hyperglycemia-induced mitochondrial superoxide overproduction activates the hexosamine pathway and induces plasminogen activator inhibitor-1 expression by increasing Sp 1 glycosylation. Proc. Natl. Acad. Sci. U. S. A. 97:12222-12226

65. Tao, Y., Howlett, A., and Klein, C. 1994. Nitric oxide regulation of glyceraldehyde-3-phosphate dehydrogenase activity in Dictyostelium discoideum cells and lysates. Eur. J. Biochem. 224:447-454.
66. Lantin-Hermoso, R.L., et al. 1997. Estrogen acutely stimulates nitric oxide synthase activity in fetal pulmonary artery endothelium. Am. J. Physiol. 273:L119-L126.

67. Garcia-Cardena, G., Fan, R., Stern, D.F., Liu, J., and Sessa, W.C. 1996. Endothelial nitric oxide synthase is regulated by tyrosine phosphorylation and interacts with caveolin-1. J. Biol. Chem. 271:27237-27240.

68. Ogonowski, A.A., et al. 2000. Effects of NO donors and synthase agonists on endothelial cell uptake of L-Arg and superoxide production. Am. J. Physiol. Cell Physiol. 278:C136-C143.

69. Massillon, D., Barzilai, N., Hawkins, M., PrusWertheimer, D., and Rossetti, L. 1997. Induction of hepatic glucose-6-phosphatase gene expression by lipid infusion. Diabetes. 46:153-157.

70. D’Ambra, R., Surana, M., Efrat, S., Starr, R.G., and Fleischer, N. 1990. Regulation of insulin secretion from beta-cell lines derived from transgenic mice insulinomas resembles that of normal beta-cells. Endocrinology. 126:2815-2822. 